DOCTRINA

\title{
La cultura de la cancelación en redes sociales: Un reproche peligroso e injusto a la luz de los principios del derecho penal
}

\author{
Cancel culture in social media: A dangerous and unfair reproach \\ according to the principles of criminal law
}

\author{
Karen Isabel Cabrera Peña \\ Universidad del Norte, Colombia
}

\author{
Carlos Alberto Jiménez Cabarcas \\ Universidad Libre Seccional Barranquilla, Colombia
}

\begin{abstract}
RESUMEN La cultura de la cancelación es un fenómeno social que se desarrolla en las redes sociales de internet que busca reprochar a aquellas personas que han asumido actitudes o comportamientos que son mal vistos socialmente, aun cuando dichas conductas no constituyen un delito. Este artículo busca demostrar a través de los principios del derecho penal que, si bien es un movimiento que trae consecuencias positivas, como visualizar y propender por los derechos de las minorías, también es una forma no institucionalizada de regular de manera desproporcionada la justicia, ya que, entre otras cosas, transgrede los mínimos derechos de quien es cancelado.
\end{abstract}

PALABRAS CLAVE Cultura de la cancelación, redes sociales, derecho penal.

ABSTRACT The cancel culture is a social phenomenon on the internet social network that pretends to reproach those people who have assumed attitudes or behaviors that are socially frowned upon, even when said behaviors do not constitute a crime. This article seeks to demonstrate, through the principles of criminal law, that it is a movement that brings positive consequences such as visualizing the rights of minorities, but it is also a non-institutionalized way to regulate justice disproportionately because it transgresses the minimum rights of people that have been canceled.

KEYWORDS Cancel culture, social media, criminal law. 


\section{Introducción}

Aunque el concepto de red social es de larga data, con el auge de la tecnología y los entornos digitales se ha convertido en una construcción social que genera mejores y más rápidos procesos de comunicación e intercambio de información a través de internet. Entre sus ventajas se encuentra que concibe nuevos movimientos de opinión, crea grupos de personas que comparten intereses y, entre otras cosas, ha generado servicios que facilitan la vida en comunidad (Cornejo y Tapia, 2011).

Tal vez uno de los mayores beneficios de las redes sociales es la oportunidad que otorga a grupos sociales, especialmente minorías, de comunicar sus necesidades, sentires y, como consecuencia, ser visualizados. De esta forma, no cabe duda que las redes sociales en internet son un medio de libertad de expresión, en donde los individuos, a través de sus perfiles, pueden exteriorizar aquello que consideran para que sus seguidores y, en general, usuarios de la red conozcan su sentir u opinión.

Con las ventajas señaladas, hace poco tiempo nació el movimiento de la cultura de la cancelación, que tiene como fin multiplicar información, bien sea a través de una publicación, video o testimonio, que es considerada inconveniente u ofensiva, para que una persona, su protagonista, sea «cancelada». ${ }^{1}$ En otras palabras, busca retirar de la vida laboral y de espacios sociales — hasta perder su reputación- a aquel individuo que se le reprocha un hecho socialmente incorrecto.

Como consecuencia, estas denuncias en redes sociales toman relevancia debido a que procuran regular comportamientos e ideologías que son condenadas ante sistemas de justicia que se cree que no sirven o son demasiado lentos. ${ }^{2}$ En este mismo sentido, visualiza, al viralizar la información, casos de repercusión mundial, lo que hace que las autoridades le presten mayor atención o que, por lo menos, sean conocidos por una gran cantidad de personas.

A pesar de las ventajas señaladas, la cultura de la cancelación se ha convertido en una vía, sin ninguna clase de límites, para sancionar a personas por conductas que, aun siendo mal vistas por la sociedad, no constituyen delito, afectándolas de manera desproporcionada en cuanto a sus prerrogativas, como el derecho a ser escuchado y el derecho a la presunción de inocencia.

Teniendo en cuenta lo anterior, este artículo pretende demostrar cómo la cultura de la cancelación, a través de los principios del derecho penal, termina siendo una medida desmesurada y desproporcionada que vulnera los derechos fundamentales que se supone han sido protegidos y salvaguardados a través de la ley.

1. Juan Carlos Delgado, «¿Qué es la “cultura de la cancelación”? La práctica de moda en la ultraizquierda», $A B C$, 10 de julio de 2020, disponible en https://bit.ly/3qyNDgR.

2. Andrés Barba, «Cultura de la cancelación», El País, 5 de diciembre de 2019, disponible en https:// bit.ly/3sCahHw. 
Para llegar al fin propuesto, a través de una revisión de archivo que incluye estudio de leyes, noticias y doctrina, entre otros, se desarrolla primero el concepto de la cultura de la cancelación y cómo ha venido evolucionando desde su nacimiento. Segundo, se estudian los principios del derecho penal y la justificación de su existencia. Tercero, se analiza la vulneración de los principios del derecho penal en la cultura de la cancelación. Para esto, se revisan algunos casos emblemáticos sobre este fenómeno, con la finalidad de entender cómo funciona dentro de las redes sociales en internet y, posteriormente, desde los principios rectores del derecho penal, se identifica cuáles son las implicaciones y consecuencias que trae para la sociedad esta clase de movimiento.

Por último, a partir del análisis se concluye que la cultura de la cancelación, por ser un movimiento social no institucionalizado, presenta dificultades para ser regulado, pues podrían vulnerarse derechos como la libertad de expresión. De todos modos, debido a las repercusiones negativas que puede traer para quien es cancelado, es pertinente tomar medidas como concientizar y educar a los usuarios y estudiar, desde diferentes ciencias afines, otras formas de control.

\section{De las redes sociales y la cultura de la cancelación}

Aun cuando hoy se habla de redes sociales para hacer referencia al uso de herramientas interactivas de internet que permiten que la gente se comunique, el nacimiento de este concepto, según las ciencias sociales, se remonta a las primeras comunidades humanas, en las que un conjunto indeterminado de actores estaban vinculados a estructuras sociales en las que se producían procesos de comunicación y transacción entre ellos (Aguirre, 2011: 5).

En el caso de las redes sociales en internet, a principio de los años setenta, con el nacimiento de la era de la tecnología de la información, la red era considerada una herramienta de control que estaba al servicio de corporaciones gigantes y gobiernos burocráticos. Algunos años después, a finales de los años setenta, el mundo digital es tomado como la tecnología de la información, que es un medio de liberación alternativo (van Dijck, 2019: 20), gracias en parte a que estas redes permiten la participación y colaboración de varias personas a través de plataformas para que se conecten y se encuentren espacialmente en lugares distintos o pertenezcan a distintas comunidades.

En otras palabras, las redes sociales en internet son plataformas web que tienen como fin la creación de comunidades en línea mediante la conexión personal de cada usuario (Ros-Martín, 2009: 554). En estos escenarios, se puede compartir información mediante la utilización de servicios agregados de mensajería personal, microblogging, publicación de fotografías, reproducción de música, formación de grupos de interés, entre otros. 
Ahora bien, teniendo en cuenta que la utilidad fundamental de las redes sociales es permitir el establecimiento de relaciones personales y el intercambio de información, estas privilegian, ante todo, la popularidad a través de perfiles y las interacciones de los usuarios y espectadores (van Dijck, 2019). Es de esta forma que están organizadas para favorecer o generar cambios de conducta, crear nuevos movimientos de opinión, promover manifestaciones, crear grupos de apoyo para causas concretas o generar una moda que incentive el consumo de un determinado producto o servicio (Cornejo y Tapia, 2011: 221).

Por ejemplo, en el campo político, el discurso público hace años únicamente se practicaba en plazas públicas, en las calles o, con mucha fortuna, por medios de comunicación públicos convencionales. Con la llegada de las redes sociales, los debates se construyen a través de estos medios, como ocurre en Twitter, llegando a más cantidad de usuarios que están localizados en diferentes partes, lo que puede también influir en el aumento de la participación social (Carbonell, 2016: 12).

Asimismo, gracias a las redes sociales, las minorías étnicas se han vuelto más fuertes al tener un espacio abierto para compartir experiencias culturales. Plataformas como Twitter y Facebook son una voz colectiva para grupos sociales marginados que tradicionalmente han sido rezagados y que por razones de discriminación se han apartado de conversaciones públicas; mientras que Youtube y Netflix han colaborado a diversificar y expandir distintos contenidos, diferentes a los convencionales, lo que democratiza el arte y genera mayor variedad cultural. ${ }^{3}$

Esta nueva forma de comunicación, si bien trae como ventaja la información, comunicación, entretenimiento y nuevas formas de comercializar de bienes y servicios, también puede generar inconvenientes, ya que se constituyen conexiones en temas que, además de importantes, son sensibles y polarizados, como la política, la religión y lo relacionado con lo social y sexual, entre otros (Cornejo y Tapia, 2011: 221), que pueden herir susceptibilidades, además de generar conflictos y violencia.

Adicional a lo anterior, las subjetividades en estos temas y la socialización que se haga sobre ellos pueden llegar a confundir la expresión personal con la mercantilización de la identidad propia, pues la intimidad y la honra de las personas se convierten en bienes que, además de venderse, pueden juzgarse y ponerse en tela de juicio (van Dijck, 2019: 20).

Aun cuando existen medidas tecnológicas para proteger la privacidad de las personas y que los usuarios de las redes sociales pueden decidir sobre la clase de información que desean publicar, lo cierto es que lo que circula en internet corre de manera rápida y se expande sin ningún control, y en el caso de las redes sociales, los comentarios, videos y fotos compartidas, aun cuando estén en perfiles privados,

3. Aja Romano, «Why we can’t stop fighting about cancel culture», Vox, 25 de agosto de 2020, disponible en https://bit.ly/zetjwBw. 
se han propagado en un espacio fundamentalmente público, en donde difícilmente pueden reservarse, tenerse vigilancia sobre su uso y que, además, pueden permanecer en la nube durante mucho tiempo (Cornejo y Tapia, 2011: 222).

En razón de lo anterior, es que las redes sociales han creado políticas con lineamientos para su uso. Pero, finalmente, son los usuarios los que deciden qué tipo de archivos y de fotografías comparten, con quién lo comparten y cuáles son las medidas de seguridad personal e informática que usan para conectarse a estas redes (Hütt, 2012: 123). De todos modos, el control de la intimidad no es absoluto, debido a que en internet no circula únicamente la información que la persona ha decidido publicar sobre ella misma, sino también la que otros quieren compartir, aun sin la autorización, de quien es protagonista de la información, foto o video que se expande por la red.

Como consecuencia de estas sinergias que son posibles a través de las redes sociales es que nace el movimiento de la cultura de la cancelación, el que - aunque no existe mayor literatura formal sobre el tema (Saint-Louis, 2021)—, según Norris (2021: 4) se refiere a las estrategias que usan activistas para crear presión social o condenar a algo o alguien por ser ofensivo; otros, como Teixeira da Silva (2021: 3), indican que hace alusión al uso que se hace de las redes sociales o plataformas públicas para cancelar la reputación de una persona pública como respuesta a un evento social negativo o escándalo. Como se observa, las definiciones tienen un punto de encuentro que es reprochar algo que es visto como malo o negativo.

Respecto a las consecuencias, la cultura de cancelación busca que la persona o personas sean retirados de espacios sociales y laborales, pierdan prestigio o posicionamiento en cierto mercado. ${ }^{4}$ De igual forma, una de las consecuencias que buscan quienes multiplican la información sobre lo reprochado ${ }^{5}$ es visibilizar las voces de las minorías (Duque, Rivera y LeBlanc, 2021: 11). Así, la cultura de la cancelación, que comenzó con denuncias contra grandes marcas, artistas famosos, dirigentes políticos, hasta afectar a ciudadanos del común, ${ }^{6}$ también se materializa cuando usuarios de redes sociales denuncian - a través de sus perfiles-a personas por hechos que han realizado que son considerados poco morales, políticamente incorrectos o deshonrosos, o cuando se publican videos, audios y chats en los que personas también están realizando conductas de este tipo. ${ }^{7}$

4. Steve Katz, «Cancel culture», Label \& Narrow Web, 4 de marzo de 2021, disponible en https://bit. ly/3pHuJFn.

5. Delgado, «Qué es...».

6. F. J. B., «Los matices de la cultura de cancelación», El Universal, 22 de julio de 2020, disponible en https://bit.ly/zesbZmE.

7. Victoria de Masi, «La cultura de la cancelación, la nueva variante del escrache», Clarín, 31 de agosto de 2020 , disponible en https://bit.ly/3 $\mathrm{EwOuU}_{3}$. 
Este movimiento nace cuando la denuncia en las redes sociales se toma como una forma para tratar de regular, mediante el oprobio social, ciertas comportamientos e ideologías que se entienden debe ser corregidas ante sistemas de justicia que no sirven, son demasiado lentos o ante conductas que, si bien no se constituyen en delitos, sí deben ser mal vistas. ${ }^{8}$ Como consecuencia de lo anterior, la cultura de la cancelación se convierte en una vía para sancionar a aquellos que han salido impunes o ilesos ante tales comportamientos.

Según Ros-Martín (2020: 2), el primer antecedente de la cultura de la cancelación tuvo lugar en Twitter cuando se le hacían llamados de atención a oficiales públicos o celebridades por ser racistas, homofóbicos o sexistas, entre otras, como una forma de justicia social y activismo. Como el mismo autor señala, la tendencia se extendió vía hashtags cuando se denunciaba un comportamiento y este se volvía viral, como sucedió con el movimiento \#MeToo, que fue creado por Tarana Burke, una mujer afroamericana, activista y sobreviviente de abuso sexual (Aggarwal y Brenner, 2019: 34) y que tomó aún más fuerza cuando en 2017 se usó el mismo para denunciar los acosos sexuales que habían sufrido varias mujeres por el productor de cine Harvey Weinstein (Ros-Martín, 2020: 4).

De igual forma, la cultura de la cancelación ha puesto sobre la mesa grandes debates sobre temas actuales como el racismo y el manejo de la fuerza por parte de las autoridades públicas, ${ }^{9}$ como ocurrió con las protestas de Black Lives Matter cuando se conoció el video de la muerte de un hombre a manos de policías, ${ }^{10}$ creando simpatía hacia las víctimas y apoyo a aquellas personas que fueron injustamente tratadas y que no podían alzar su voz y hasta abriendo discusiones públicas sobre temas como el estatus migratorio de minorías y la proliferación de grupos extremistas en Estados Unidos (Duque, Rivera y LeBlanc, 2021: 2).

En el caso de las personas que son denunciadas, como consecuencia del reproche social, son - como ya se comentó- apartadas de sus trabajos, señalados y censurados, aun por publicaciones de hace años atrás o después de haber manifestado su vergüenza y ofrecido disculpas por lo dicho o hecho, ${ }^{11}$ lo que trae consigo algunos efectos negativos al movimiento.

Primero, dado que la persona que es denunciada muchas veces no logra ser escuchada o sus argumentos para justificar lo hecho o dicho no son tenidos en cuenta, se crea una radicalización del discurso (Anderson-López, Lambert y Budaj, 2021: 71), lo

8. Barba, «Cultura...».

9. Rob Henderson, «What propels cancel culture: Human nature may lead people to magnify moral transgressions», Psychology Today, marzo-abril de 2020, pp. 36-38.

10. F. J. B., «Los matices...».

11. Barba, «Cultura...». 
que también deja por fuera la oportunidad de debatir y replicar sobre lo sucedido. ${ }^{12}$ Así pues, las declaraciones, sobre las denuncias y la misma denuncia en sí incitan a la provocación, lo que puede desembocar en actos de violencia, pues la cancelación puede versar sobre asuntos en los que una persona tiene una diferencia de pensamiento y otro no está de acuerdo. ${ }^{13}$

Sobre la radicalización del discurso, la cultura de la cancelación puede recaer sobre chistes o frases irónicas o parodias que por algunas personas son tomadas como ofensivas o intencionadas a causar daño. ${ }^{14}$ En este caso, la cancelación puede ser una limitante a la libre expresión y una forma de intolerancia y empatía ante la forma de comunicarse y de pensar de otro. ${ }^{15}$

Segundo, dado que la cancelación se centra en la denuncia y en afectar de todas las maneras posibles al agresor, no se entablan procesos de conversación o reconocimiento para tomar ventajas sobre lo sucedido y generar cambios positivos. ${ }^{16}$ Por el contrario, las personas canceladas son rezagadas y marginadas, desconociéndoseles su talento o quehacer, lo que tampoco permite que vivan procesos de aprendizaje y crecimiento. ${ }^{17}$

Por último, tomar la cultura de la cancelación como un mecanismo de justicia para reprender al supuesto agresor también desconoce las luchas civiles que se han llevado a cabo a través de los años a partir de figuras jurídicas para sancionar, según la ley, a quien cometen actos que realmente afectan la integridad de las personas. ${ }^{18}$

Como conclusión, la cultura de la cancelación es un movimiento que ha visibilizado agresiones y actos impropios a través de redes sociales como una forma de reprender y reprochar a quien los cometen. Por otro lado, a pesar de sus ventajas, también puede llegar a ser un espacio que margina y castiga, sin opción de ser escuchado, de manera muy severa a quien ha cometido actos que, en muchos casos, aun sin ser ilegales, son considerados inmorales.

Como señala la escritora Ayishat Akanbi en un video publicado en Double Down,19 la cultura de la cancelación es un tema complejo, ya que los seres humanos se inte-

12. F. J. B., «Los matices...».

13. Romano, «Why we can't...».

14. Henderson, «What propels...».

15. Marina de la Torre, «La "cultura de la cancelación": El fin del arte... y de la libertad», Disidentia, 2 de octubre de 2019, disponible en https://bit.ly/3qs5rtG.

16. Leah Asmelash, «Why “cancel culture” doesn’t always work», $C N N, 21$ de septiembre de 2021, disponible en https://cnn.it/3EtQ6oJ.

17. Sarah Hagi, «Cancel culture is not real. At least not in the way people think», Time, 21 de noviembre de 2019, disponible en https://bit.ly/3qBJQ2m.

18. Hagi, «Cancel culture...».

19. Ayishat Akanbi, «The problem with cancel culture», Double Down, 21 de enero de 2020, disponible en https://bit.ly/3mFYOmz. 
ractúan de distintas maneras que pueden llegar a ser complejas, y es así como las relaciones que se desarrollan dentro de las redes sociales terminan siendo aún más difíciles de entender y estudiar. En este mismo sentido, indica que, como seres humanos complejos, las personas también pueden cambiar su forma de comportarse y pensar, y es por esto que la cultura de la cancelación puede llegar a ser un arma para afectar la salud mental de las personas, pues cancelarlas puede ser un llamado de atención muy fuerte, cuando lo que debería hacerse es incentivar a los demás a ser más tolerantes y amables.

\section{Breve historia del derecho penal y la pertinencia de sus principios rectores}

En las sociedades modernas, el ejercicio de la fuerza, como método de control social, encuentra su titularidad en el Estado. Esta facultad para limitar derechos, restringir libertades, coartar garantías, ejercida por quien ostenta el poder - bien sea príncipe, dictador, canciller, presidente, etcétera- recibe el nombre de poder punitivo. Sin embargo, por más honesto y sensato que sea un gobernante, siempre será necesaria una regulación que se debe respetar para ejecutar el poder punitivo, toda vez que, como expresó lord Acton, «el poder tiende a corromper y el poder absoluto corrompe absolutamente». ${ }^{20}$

Con el fin de no caer en el ejercicio arbitrario de la fuerza, y con esto garantizar el efectivo ejercicio de los derechos fundamentales, resulta indispensable la observancia de requisitos mínimos para la aplicación del poder punitivo por parte de quien legítimamente posee el poder. A este conjunto de límites al poder punitivo del Estado se le denomina derecho penal (Zaffaroni, 2007: 25).

Bajo esta perspectiva, los miembros de la sociedad facultan al Estado a ejercer el poder punitivo de una manera positiva, con la finalidad de mantener el orden en el complejo sistema social, y es empleado para proteger bienes jurídicos ante agresiones injustificadas (Roxin, 2007: 444). De esta forma, se denomina como delito a aquel atentado - a título de lesión o peligro- a bienes jurídicos realizado mediante una conducta culpable, previamente descrita por el legislador. En este sentido, el poder punitivo encuentra su límite en lo que se define como delito, encontrándose el Estado únicamente para ejercerlo cuando se verifique esta forma de conducta punible (Agudelo, 1987: lxi).

Los antecedentes del derecho penal se encuentran en Inglaterra, cuando en 1215, con la Carta Magna reconoce en el numeral 39, del derecho a la libertad, que podrá solo ser restringido en virtud de una sentencia judicial; asimismo, en el numeral si-

20. John Emerich Acton, «Letter to Archbishop Mandell Creighton», 5 de abril de 1887, en Handover College, disponible en https://bit.ly/3etEtMG. 
guiente, indica que la justicia es un derecho al acceso de todos. Lo anterior permite evidenciar que el ejercicio del poder punitivo, además de estar consignado en un sistema, estaba condicionado a una decisión adoptada mediante una sentencia, producto de un proceso judicial.

Como característica del Estado moderno, en 1662, Locke dispuso en su Segundo tratado de gobierno que la potestad estatal para intervenir en la libertad de los individuos solo puede ejercerse en los casos necesarios y con la magnitud imprescindible para satisfacer las exigencias derivadas de los derechos de los demás y de los intereses esenciales de la comunidad, por lo que el disfrute de la libertad es la regla general y sus límites por intervención estatal resultan excepcionales, reducidos únicamente a lo inexcusable (Bernal, 2014: 56). Queda evidente, según lo dicho, cómo las penas manifestación de intervención estatal a las libertades personales de los individuosdeben mantenerse dentro de los límites del principio de proporcionalidad, al establecer que deben estrictamente contar con la intensidad necesaria para que, a través de estas, se garantice el disfrute de los derechos de los asociados.

De esta forma, la legitimidad del Estado para sancionar está dada por la voluntad libre de los asociados de vincularse a la sociedad. Es decir, el Estado no puede sancionar a quien no hace parte de la sociedad, por ser la pena una consecuencia prevista en el contrato social. La garantía del disfrute de sus libertades es la razón última para que el hombre forma parte del contrato social, a cambio de soportar una eventual y excepcional intervención, solo cuando resulte estrictamente necesario. Así las cosas, las penas, solo podrán legitimarse en la medida que se correspondan con este fin perseguido (Bernal, 2014).

A pesar de lo anterior, a mediados de 1764, el milanés Cesare Beccaria presenta de manera anónima al mundo su obra Dei delitti e delle pene (De los delitos y las penas), como una crítica al abuso de la fuerza por las autoridades italianas ante los presuntos perpetradores de delitos, de la cual él mismo sufrió en carne propia, al haber sido enjuiciado y confinado en prisión tras ser denunciado por su propio padre por mantener una relación sentimental no aceptada por este (Beccaria, 1993: 20).

De los delitos y las penas se erige como un hito en la literatura de la justicia penal contemporánea, pues las aseveraciones del marqués de Beccaria se constituyeron en los principios rectores en los que se funda en derecho penal moderno. Dentro de estos principios, solo por nombrar algunos, se encuentran la proporcionalidad entre la pena y el daño ocasionado, el derecho a la presunción de inocencia, el debido proceso y la proscripción de la pena de muerte (Bustos, 1999: 109).

Destaca el autor milanés que la reacción estatal debe corresponderse con la gravedad del daño ocasionado, cuando señala que «más fuertes deben ser los motivos que retraigan los hombres de los delitos a medida que son contrarios al bien público, y a medida de los estímulos que los inducen a cometerlos. Debe por esto haber una proporción entre los delitos y las penas» (Beccaria, 1993: 68). 
Esta obra resonó en las legislaciones internas de diferentes naciones y sirvió de fundamento para eventos políticos y sociales tan importantes como la Revolución francesa, toda vez que en la Declaración de los Derechos del Hombre y el Ciudadano de 1789, en los artículos 6, 7 y 8 pueden vislumbrarse algunos de los principios y garantías de orden procesal enunciados por Beccaria veinticinco años antes (Leyva y Lugo, 2015: 136), en que se destacan el principio de legalidad, igualdad ante la ley y debido proceso.

Estos principios propios del modelo de Estado legalista, como una superación al Estado absolutista, encontraron en la ley la cura contra la arbitrariedad del rey, pues las autoridades estatales deberían, a partir de estos postulados, actuar solo conforme a la ley, y la ley es la expresión del pueblo (Montesquieu, 1906: 225). Por lo que, para estos tiempos, antes de la Segunda Guerra Mundial, el derecho penal, entendido como límite al poder punitivo del Estado, se materializaba en el contenido del enunciado legislativo. En otras palabras, el soberano pasó de ser el elegido de Dios (monarca), al pueblo que se expresa a través del Parlamento, quedando las autoridades estatales limitadas a sus mandamientos.

Luego de que la humanidad presenció los horrores a los que fueron sometidos principalmente los judíos por el régimen nacionalsocialista, y que estas prácticas en gran medida fueron orquestadas por el mandatario legítimo de turno, a través de la expedición de leyes y demás actos jurídicos con «legitimidad» formal, fue evidente que el clamor del pueblo representado en leyes resultaba insuficiente para limitar en debida forma el poder punitivo estatal. Razón por la cual se cambió de un Estado legalista a uno constitucional, en el que el límite al ejercicio de la fuerza se encuentra en el respeto por los derechos fundamentales y al reconocimiento del valor supremo como lo es la dignidad humana (Bachof, 1985: 46).

Resultado de esto, la Asamblea General de las Naciones Unidas presenta al mundo la Declaración Universal de Derechos Humanos de 1948, apenas tres años después de la culminación de la Segunda Guerra Mundial, en el que en reconocimiento de la dignidad humana se consigna la igualdad sin distinción de raza, color, sexo, idioma, religión, opinión política o de cualquier otra índole, origen nacional o social, posición económica, nacimiento o cualquier otra condición (artículo 2); presunción de inocencia (artículo 11) derecho a la intimidad y a la honra (artículo 12); derecho a la propiedad (artículo 17); libertad de pensamiento y credo (artículo 18) y expresión (artículo 18); proscripción de la esclavitud (artículo 4), tortura (artículo 5), detención arbitraria (artículo 9); derecho al trabajo (artículo 23); derecho al ingreso mínimo vital (artículo 25); derecho a la cultura (artículo 27) y libre desarrollo de la personalidad (artículo 29).

Por otro lado, el Pacto Internacional de Derechos Civiles y Políticos del 16 de diciembre de 1966 establece el principio de doble instancia para sentencias penales condenatorias, debido proceso (artículo 14), la aplicación excepcional de la pena 
capital (artículo 6) y el principio de favorabilidad (artículo 15). Asimismo, la Convención Americana sobre Derechos Humanos de San José de Costa Rica de 1969 dispuso la prohibición de restablecimiento de la pena capital donde ya haya sido abolida (artículo 4), los efectos personales de la pena (numeral 3, artículo 5), trato diferencial de los condenados con los procesados (numeral 4, artículo 5), y la reforma y readaptación social de los condenados como finalidad de la pena (numeral 6, artículo 5).

Todo este conjunto de derechos se convierte en una carga para los Estados del mundo, en el sentido de que sus ordenamientos jurídicos internos deben garantizar a sus asociados como mínimo las garantías aquí consignadas, sin perjuicio de que puedan ofrecer un mejor estándar de garantías.

En ese acuerdo de respeto por estos derechos, ningún ordenamiento jurídico podrá entonces disponer normativamente que de manera legítima se atente contra estas disposiciones, lo que supone que ningún Estado podrá disponer políticas, ni siquiera con el visto bueno de todos los miembros del respectivo pueblo, que generen discriminación que de manera arbitraria se les restrinjan garantías fundamentales a las personas, se les someta a sanciones que atenten contra sus derechos fundamentales, etcétera. En otras palabras, por encima de la voluntad popular se encuentra el respeto por la dignidad humana de todas las personas, no solo en razón de su sexo, raza, religión, etnia, etcétera, sino también de los actos cometidos (Velásquez, 2017: 43).

De esta forma, ninguna situación en la que se encuentre un ser humano podrá hacer desaparecer su dignidad humana, aquel valor que se erige como principal fuente de derecho penal, entendido como un límite al poder punitivo del Estado (Sotomayor y Tamayo, 2017: 24).

A manera de conclusión, los principios rectores del derecho penal corresponden a medidas históricamente constituidas que buscan evitar y cesar la arbitrariedad en la que puede verse inmerso un individuo que está siendo juzgado por la vulneración de bienes jurídicos que están legalmente protegidos. Es así como se busca mantener el orden jurídico y social, salvaguardando las prerrogativas fundamentales de las personas, como es la dignidad humana.

\section{Vulneración de los principios del derecho penal en la cultura de la cancelación}

En este aparte se hace una sistematización y delimitación de algunos casos emblemáticos sobre la cultura de la cancelación con la finalidad de entender y analizar la forma cómo funciona dentro de las redes sociales. Posteriormente, desde los principios rectores del derecho penal, se identifica cuáles son las implicaciones y consecuencias que puede traer para la sociedad esta clase de movimiento. 


\section{Sistematización y delimitación de algunos casos emblemáticos de la cultura de la cancelación}

La sistematización de los casos se hace primero a partir de aquellos que versan sobre conductas del cancelado que no son condenadas, pero que tienen repercusiones y reproches severos por quienes cancelan; segundo, sobre casos de conductas inmorales efectuadas por el cancelado, pero de escasa gravedad penal; $y$, por último, casos de conductas ilegales ejecutadas por el cancelado, pero que no revisten necesariamente una pena.

En el primer escenario, casos de conductas que no son condenadas o que no lo son con severidad por quienes cancelan, se encuentra lo sucedido al actor Kevin Spacey, que fue acusado de abuso sexual y malas conductas por varios hombres y, aunque negó las denuncias y los cargos fueron desestimados en un único caso que fue llevado a los tribunales, ${ }^{21}$ este fue apartado del papel principal que tenía dentro de una las series estadounidenses más vistas y reemplazado en el elenco de una película que estaba próxima a grabarse. ${ }^{22}$ En este caso, la cancelación de Spacey acabó con su carrera como actor y, además, sigue tachado como abusador sexual a pesar de que, según el sistema legal, no ha cometido ningún delito.

Otro caso que causó gran controversia es el del desarrollador de juegos Alec Holowka, que fue acusado en redes sociales por Zoë Quinn, quien era su pareja en aquel momento, de abuso físico, sexual y sicológico. Cuando la denuncia se hizo pública con los hashtags \#gamergate y \#Metoo, el desarrollador fue cancelado en su trabajo y su vida social, lo que lo llevó a suicidarse sin que fuera escuchada su versión de la historia o hubiera tenido lugar a defenderse de las acusaciones ${ }^{23}$ ante un juez y por medio de un proceso legal. Más tarde la declaración de la expareja del desarrollador fue borrada; sin embargo, ya la «corte de la opinión pública» lo había sentenciado y, como consecuencia, perdió su vida. ${ }^{24}$

Por último, esta clase de casos de la cultura de la cancelación también permea a personas anónimas, como es el caso de Amy Cooper, quien fue cancelada cuando por redes sociales se dio a conocer un video en el que, mientras paseaba a su perro por Central Park de Nueva York, en medio de una discusión con un hombre afroamericano llamaba a la policía alegando que este estaba amenazando su vida cuando él mantenía distancia y no tenía contacto físico con ella (Miles, 2020). ${ }^{25}$

21. De la Torre, «La «cultura...».

22. Susannah Goldsbrough, "Cancel culture: What is it, and how did it begin?», The Telegraph, 30 de julio de 2020, disponible en https://bit.ly/3sAOuQJ.

23. Diana Davison, «Allegations that led to Alec Holowka’s suicide need proper scrutiny», Post Millenial, 3 de septiembre de 2019, disponible en https://bit.ly/3HiTJZe.

24. Rick Rottman, «Zoë Quinn accuses Alec Holowka of sexual abuse, he then kills himself», 1 de septiembre de 2019, disponible en https://bit.ly/3sBE3fx.

25. Frank Miles, "Amy Cooper charged in Central Park confrontation seen in viral video», Fox News, 
El video de la escena relatada rápidamente se hizo viral, y aunque la mujer reconoció que no era cierto que estaba siendo amenazada y pidió disculpas, la empresa donde trabajaba decidió despedirla. ${ }^{26}$ En este caso, cabe preguntarse si la medida idónea y proporcional era presentar una denuncia por calumnia o si, por el contrario, haber perturbado la vida de Amy tendrá como consecuencia que haya menos racismo y que ella actúe ante situaciones similares de manera diferente.

De los casos de conductas inmorales, pero de escasa gravedad - que son los más comunes-, en 2017, el comediante Louis C. K. fue cancelado cuando se conocieron, a través de redes sociales, acusaciones de tener comportamientos sexuales erráticos con mujeres. Producto de estas, las cuales fueron aceptadas por el actor y de las que pidió disculpas públicas, ${ }^{27}$ le cancelaron su programa de televisión y sus trabajos cinematográficos; de igual forma, su gira no estuvo disponible por un tiempo considerable. ${ }^{28}$

A pesar de lo anterior, después de diez meses el comediante pudo reprogramar las fechas de su gira y aunque sus espectáculos aún tienen gran acogida en las redes sociales donde se promociona su trabajo o se hace referencia a él, se le critica y acusa por su comportamiento del pasado. ${ }^{29}$ Como se observa con este ejemplo, la cultura de la cancelación tiene trascendencia en el tiempo, pues si bien el señalado pudo retomar su vida - sobre todo cuando las actuaciones no revisten un delito-, es todavía recordado por el evento negativo que lo llevó a ser anulado de su vida social y profesional.

Otro caso de cultura de la cancelación con connotación moral que fue altamente comentado es el del comediante Kevin Hart, que declinó ante la propuesta de presentar los premios Oscar en 2018, por ser acusado de homofóbico por unos tuits que había publicado en 2011. ${ }^{30}$ Sobre esta situación, el comediante, además de pedir disculpas, aseguró que no era justo ser marginado por chistes homofóbicos que había publicado tantos años atrás, pues no era la misma persona de aquel momento y al ser cancelado se le estaba «juzgando» sin tener en cuenta que cualquier persona en cualquier momento puede cometer un error. ${ }^{31}$

6 de julio de 2020, disponible en https://fxn.ws/3sGkVo2.

26. Carlos Hernández-Echevarría, «Despedido por racista: Verdades y mentiras de la "cultura de la cancelación”", El Diario, 14 de julio de 2020, disponible en https://bit.ly/3JmReqI.

27. Goldsbrough, «Cancel culture».

28. Erin Bunch, «The cancel-culture glossary for canceling, boycotting, calling out, and calling in», Well+Good, 23 de julio de 2020, disponible en https://bit.ly/3Hj2x1u.

29. Benjamin Fearnow, «Louis C. K. sparks "comedy police", cancel culture debate after Auschwitz Joke in Israel», Newsweek, 30 de noviembre de 2019, disponible en https://bit.ly/343yOex.

30. Justin Glover, «"Cancel culture” a double-edged sword», The Daily Herald, 23 de octubre de 2020, disponible en https://bit.ly/32ptD8n.

31. «Kevin Hart slams cancel culture», MSN News, 27 de octubre de 2020, disponible en https://bit. ly/3mGVRSC. 
Así también, en el 2020, la autora de los famosos libros de Harry Potter, J. K. Rowling, fue cancelada por varios grupos debido a que hizo comentarios ofensivos a través de su sitio web y su perfil de Twitter contra las personas transgénero. ${ }^{32} \mathrm{Como}$ resultado de sus declaraciones, la comunidad LGBTI emitió su desaprobación por lo dicho por la autora, pues, según ellos, lo comentado se constituye en una negación a los derechos humanos de este grupo; también los actores de las películas basados en sus libros también hicieron pública su cancelación. ${ }^{33}$

Aun cuando la escritora fue cancelada en redes sociales, esta se negó a disculparse y en compañía de más de 100 figuras públicas, como Margaret Atwood — autora de la novela El cuento de la criada, y que también fue cancelada en 2016 por apoyar al novelista Steven Galloway, que fue despedido de la Universidad de Columbia Británica de Canadá por acusaciones de agresiones sexuales en su contra- ${ }^{34}$ publicó una carta en el Harper's Magazine en la que señala que la cultura de la cancelación es una forma de perder el debate abierto y la tolerancia hacia la diferencia. ${ }^{35}$

Entre otras cosas, esta carta señala que aun cuando el mundo se constituye como una sociedad liberal, el intercambio de la información y de las ideas cada día se ha visto más restrictivo, ya que hay una visión más radical de los derechos y la censura ha permeado a la sociedad a través de movimientos como la cultura de la cancelación. Como consecuencia, hay poca tolerancia a los puntos de vista opuestos y una tendencia a resolver problemas políticos que son complejos a través de argumentos morales, lo que transgrede el debate y el libre pensamiento. ${ }^{36}$

Por último, sobre los casos de conductas ilegales realizadas por el cancelado, pero que no revisten necesariamente una pena, se encuentra lo sucedido con el reconocido golfista Tiger Woods, quien en noviembre de 2009, después de un accidente de tránsito, se descubre que le fue infiel repetidas veces a su esposa, lo que constituye un incumplimiento de su contrato matrimonial, pero que no implica que haya cometido un delito. ${ }^{37}$ Por lo sucedido, el deportista fue fuertemente criticado y, como respuesta al escándalo, muchos de sus patrocinadores cancelaron los contratos que tenían con él..$^{38}$

32. Goldsbrough, «Cancel culture».

33. Jerry Newcombe, «Cancel culture forgets it can be canceled too», Newsmax, 15 de julio de 2020, disponible en https://bit.ly/3qytYog.

34. Deni Silva, «J. K. Rowling, Margaret Atwood y otras 150 figuras públicas firman carta condenando la "cultura de la cancelación"», Tomatazos, 8 de julio de 2020, disponible en https://bit.ly/3sFA166.

35. Goldsbrough, «Cancel culture».

36. Elliot Ackerman y otros, «A letter on justice and open debate», Harper's Magazine, 7 de julio de 2020, disponible en https://bit.ly/3JrZ5DE.

37. «Tiger Woods: When the 2009 car crash exposed his extramarital affairs», DNA, 24 de febrero de 2021, disponible en https://bit.ly/3Hg9qAl.

38. Justin Wallace, «If cancel culture is real, here are all the times it failed us», Bleu Magazine, 4 de agosto de 2021, disponible en https://bit.ly/3qpCDCe. 
De igual forma, el ciclista Lance Armstrong fue cancelado cuando fue investigado y sancionado por la Unidad Ciclista Internacional por consumir sustancias prohibidas que mejoraban su rendimiento en competencia. ${ }^{39}$ Además de habérsele retirado sus medallas y pagar una multa, también fue señalado en redes sociales y medios de comunicación como el mayor impostor en el campo deportivo, por lo que perdió muchos de sus patrocinadores y tuvo que alejarse de su vida social. ${ }^{40}$

En los casos anteriores, los deportistas sí cometieron un acto ilegal que fue conocido y sentenciado por la autoridad competente. Sin embargo, aun sin perfeccionarse un delito, fueron víctimas de reproche y señalamiento por parte de los usuarios de redes sociales.

\section{Reflexiones sobre las implicaciones de la cultura de la cancelación frente a los principios del derecho penal}

De los casos ilustrados con antelación puede evidenciarse la manera en la que la cultura de la cancelación afecta negativamente a las personas contra las cuales se dirige, pudiéndose percibir cómo la sociedad, a través de redes sociales, tacha y juzga los actos que considera inadecuados, sin que exista un filtro o medidas que impidan un ejercicio desmesurado de la cancelación, excediendo incluso los principios del derecho penal.

Si bien los hechos endilgados al comediante Louis C. K. y confesados por este no se adecúan de manera alguna a un delito sexual, su humanidad sufrió las consecuencias de la cancelación, pues su mínimo vital y su derecho al trabajo, establecidos en el artículo 25.1 y 23.1 de la Declaración Universal de Derechos Humanos, respectivamente, se vieron vulnerados con la supresión de su actividad profesional, teniendo en cuenta su calidad de personaje público, a quien la sociedad le exige un estándar diferencial respecto al ciudadano común.

Si bien resulta evidente que su comportamiento era moralmente reprochable pero legalmente inofensivo, las consecuencias de la cancelación fueron mucho más grave que en las que pudo verse inmerso ante una sentencia condenatoria, toda vez que se estima que por el escándalo sexual dejó de percibir cerca de USD 35 millones, teniendo en cuenta los negocios que estaba acostumbrado a cerrar con televisoras, plataformas de streaming y productoras de películas. ${ }^{41}$ De acuerdo a la revista Forbes,

39. William Fotheringham, «Timeline: Lance Armstrong’s journey from deity to disgrace», The Guardian, 9 de marzo de 2015, disponible en https://bit.ly/3HgXq1M.

40. Peter Beaumont, «Was Lance Armstrong protected by a culture of bullying and secrecy?», The Guardian, 26 de agosto de 2012, disponible en https://bit.ly/3sFB3zo.

41. Anneta Konstantinides, “I’ve been to hell and back": Louis C. K. jokes that he lost “\$35 million in an hour" and reveals he gets booed on the streets as he addresses \#MeToo scandal for the first time in a stand-up comedy set», Mail Online, 17 de octubre de 2018, disponible en https://bit.ly/3qylkie. 
para 2017 estaba en el puesto tres de los comediantes mejores pagados del mundo, con un ingreso de USD 52 millones, ${ }^{42}$ mientras que la conducta que se le endilga no tenía las características de un delito, al no haber violencia, abuso - por tratarse de mujeres mayores de edad- ni tampoco contacto físico.

Como se observa, cuando se trata de casos de cancelación por actos inmorales pero de escasa gravedad penal, se constituye una fuerte infracción al principio de proporcionalidad, pues de acuerdo a Beccaria (1993: 68) y la Declaración de los Derechos del Hombre y del Ciudadano en el artículo 8, la ley solo debe establecer penas que sean estricta y evidentemente necesarias, con la finalidad de limitar la capacidad sancionatoria estatal a aquellas medidas que sean más benignas con el derecho fundamental intervenido entre todas aquellas que revisten, por lo menos, la misma idoneidad para contribuir a alcanzar el objetivo propuesto (Bernal, 2014: 933).

De lo dicho, se puede dilucidar que la ley está dada para que existan medios que resulten menos lesivos, pero igual de idóneos, para lograr la corrección buscada, y se preferirán aquellos que menos daño ocasionen al reprendido. Este análisis también debe usarse en los casos de conductas ilegales, pero no necesariamente delictivas, ya que deben entenderse como suficientes las otras vías de derecho para alcanzar la justicia y no deben ser vistas y tratadas como si constituyeran delitos a la luz de quienes cancelan.

De esta forma, se ve cómo la cancelación termina siendo entendida como un elemento supralegal, pues satisface la necesidad de escarmiento de la sociedad contra comportamientos que el ordenamiento jurídico encuentra irrelevantes penalmente $o$ que fueron resueltas por otras vías legales. En este sentido, una sentencia absolutoria en el caso particular se convierte en un atentado contra la moral de una sociedad que se cree políticamente correcta.

En otras palabras, la cancelación colma la sed de retribución y satisface con represión social el discurso promocionado en las redes sociales, en que los usuarios convierten al señalado en un delincuente, como le sucedió al actor Kevin Spacey, que es tildado de violento depredador sexual aun cuando fue declarado inocente, o como el caso de Lance Armstrong, que fue considerado el peor fraude en el ciclismo, pero muchos más deportistas fueron también sancionados por dopaje.

Resulta pertinente resaltar que, desde el punto de vista legal, los Estados solo pueden sancionar a través de la imposición de penas cuando se lesionen o pongan en peligro los bienes jurídicos más importantes, no meros atentados a los valores éticos, ya que, si bien es indudable la aspiración ética del derecho penal, el objeto mismo de tutela de bienes jurídicos es el que le asigna un límite racional a la aspiración ética del derecho (Zaffaroni, 1998: 50). En este sentido, con la imposición de penas se busca

42. Madeline Berg, «The world's highest-paid comedians 2017: Jerry Seinfeld returns to the top spot», Forbes, 27 de julio de 2017, disponible en https://bit.ly/3sIWDCy. 
que el comportamiento lesivo no se repita. De alguna forma, concientiza a los miembros de la sociedad a no cometer delitos; sin embargo, no pretende cultivar o proteger principios morales. Como bien lo enseña Santiago Mir Puig (2011: 112):

Es evidente que ni el derecho puede regir la conciencia individual, ni la moral de un individuo puede decidir el orden colectivo del derecho. Este ha de basarse en un consenso social que en las sociedades democráticas y plurales no solo tiene por qué coincidir con cada moral individual, sino tampoco con una única moral social.

Para ejemplificar lo anterior, cuando en los casos de conductas que no son condenados los cancelados o que no lo son con severidad, como cuando la sociedad condenó a Kevin Spacey, quien se defendió y triunfó en los tribunales, quedó claro que el ejercicio del derecho a la defensa, lejos de ser entendido como una reacción apenas natural de las personas por buscar proteger su buen nombre y su libertad, se convierte en la lápida de su carrera profesional, pues la sociedad moralmente superior exige aceptación de cargos, y todo intento de defensa se entiende como un acto de justificación totalmente inaceptable.

Lo anterior, bajo la luz de los principios del derecho penal, se traduce en una violación al derecho de defensa, en particular al derecho a ser oído el acusado por parte de un ente imparcial, dictados en los artículos 10 y 11 de la Declaración Universal de los Derechos Humanos. Asimismo, apartándose de lo conceptuado en los artículos 9.4, 14.1 y 14.3 literales b), c), d), e), f) y g) del Pacto Internacional de Derechos Civiles y Políticos.

De igual manera, puesto que se ignora que las autoridades estatales — llamadas a seguir un procedimiento riguroso en la obtención de pruebas sobre la existencia de los hechos objeto de reproche- hayan encontrado inocente al actor, en este mismo ejemplo, la cancelación no conoce del principio de necesidad de la sanción, un elemento determinante al momento de la imposición de penas, de acuerdo al artículo 8 de la Declaración de los Derechos del Hombre y del Ciudadano.

Interpretando el alcance del principio de necesidad, cuando las autoridades jurisdiccionales reconocen la inocencia de un individuo, se debe porque el hecho reprochable no existió, o existiendo no es punible, o siendo punible no fue cometido por quien fue señalado de materializarlo. Por lo que, ante este escenario, un reproche social de una fuerza tan considerable como la cancelación resulta innecesario.

De igual forma, se habla de que la cancelación es el reproche social innecesario, ya que, bajo el contexto de los principios del derecho penal, la necesidad, como aquel subprincipio del principio de proporcionalidad, propende porque las restricciones deben ser las más benignas con el derecho fundamental intervenido, entre todas aquellas que revisten - por lo menos- la misma idoneidad para alcanzar el beneficio propuesto (Bernal, 2014: 933). Contrario al principio, la cultura de la cancelación excede los fines propuestos por el sistema punitivo. 
Por otro lado, como ya se estudió, los estándares sociales de lo que es catalogado «buena persona» juega un papel determinante en la cultura de la cancelación. Por ejemplo, los estándares que se esperan sobre un hombre caucásico heterosexual cualidades de la mayoría de los cancelados-, en principio colmado de privilegios, hacen que sea más fuerte el reproche cuando sea acusado de un comportamiento violento de índole sexual en contra de una mujer, ya que, por la misma finalidad de la cancelación, se busca proteger a comunidades y poblaciones marginadas como las mujeres o minorías étnicas.

En principio, esa protección genuina no está mal, pero llega a ser vulneradora de derechos cuando el señalado es presa de atentados y amenazas contra su vida por cuenta de cualquier persona que decida tomar justicia en mano propia. Si bien los Estados modernos y posmodernos permiten el ejercicio de la violencia para tutelar o proteger un bien jurídico atacado de manera injusta (Velásquez, 2017: 491), esta figura jurídica encuentra su génesis en el artículo 140 de la Constitutio Criminalis Carolina de 1532, originalmente para ser empleada contra agresiones con armas a la vida o integridad, y ello, solo si no había posibilidad de esquivar. La ciencia del derecho penal común poco a poco fue extendiendo la legitima defensa a la defensa de otros bienes jurídicos, pero autorizándola únicamente dentro del marco de la proporcionalidad (Roxin, 1997: 610), por lo que, incluso si se desea proteger un derecho fundamental, los particulares deben respetar la proporcionalidad, pues de lo contrario el ejercicio de la violencia no llega a ser más que un acto de venganza, lo que no encuentra legitimación.

De igual forma, las consecuencias pueden llegar a ser realmente lamentables, como sumergir al cancelado a la depresión, desesperación y angustia que lo llevan, como sucedió supuestamente en el caso del galardonado programador Alex Holowka, a arrebatarse su propia vida, al encontrar insuperable el daño a su reputación.

Como se observa, en la cultura de la cancelación no se diferencia entre la conducta reprochable y un delito, pues un acto mal visto o desagradable, que ni siquiera es punible y podría superarse con unas disculpas o incluso con una indemnización o sanción de civil o administrativa, termina etiquetando a una persona como incorrecta o inmoral por largos períodos de tiempo, lo que sobrepasa la esfera del derecho penal en que la persona, una vez paga la pena, se supone es parte de la sociedad.

Si bien Alessandro Baratta (2004: 84) afirma que la teoría del etiquetado (labeling approach), entendida como estatus social de delincuente que recibe quien comete delitos, lo padece únicamente quien es sujeto de represión por las instituciones estatales correspondientes (jueces, fiscales, etcétera), y no quien, a pesar de cometer crímenes, no es sometido por el sistema penal; en la actual cultura de la cancelación, el estatus de delincuente permea no solo al que comete delitos y, por alguna razón, no pasa por las manos del sistema judicial, sino también al que es encontrado inocente por las autoridades jurisdiccionales. 
Si bien el Estado protege a los miembros de la sociedad de los atentados que sufren por parte de terceros, también estos requieren protección de las mismas instituciones estatales porque, si bien el Estado ejerce de manera legítima la fuerza, también puede llegar a afectarlos en su honra, bienes, libertad y vida (Bachof, 1985). Como se señaló en apartes anteriores, estos límites están constituidos en el derecho penal al ser un límite al poder punitivo estatal. Empero, con la cultura de la cancelación se observa que la sociedad - personas de derecho privado, excluyendo de esto a las instituciones estatales-, por cuenta de las redes sociales y demás medios de comunicación, pueden lesionar, al mismo grado que las autoridades de derecho público, las prerrogativas fundamentales de cualquier persona.

En concordancia con lo anterior, las repercusiones de la cultura de la cancelación resultan en muchos grados más lesivas y menos garantistas que el control social impuesto desde las autoridades estatales, por lo que debería, así como con el poder punitivo, pensarse en formas de limitarse.

Sin embargo, la mayor dificultad consiste en que, si bien existen políticas de uso para cada una de las redes sociales que podrían reformularse, estas no pueden coartar la libre expresión de los usuarios, bien sea para denunciar casos «inmorales» o pronunciarse sobre cualquier asunto sensible, censurando contenido por suponer que puede llegar a ser lesivo. De igual manera, la cultura de la cancelación, al ser una clase de control social, no siempre tiene consecuencias negativas, ya que también es una forma de evidenciar problemáticas de forma más expedita resaltando, también, la voz de minorías. ${ }^{43}$

De otra forma, parece ser que la solución respecto al control de la cultura de la cancelación está en la educación y conciencia que tomen los usuarios respecto a las repercusiones que tienen esta clase de denuncias y, de igual manera, sobre cómo todo lo comentado en estas redes sobre esferas delicadas, como las políticas y sociales, afectan los derechos de otras personas. Todo lo anterior, en pos - como lo hace el derecho penal - de permitir que se viva en armonía, pues lo menos deseado es sufrir retrocesos en el reconocimiento de los derechos mínimos de los ciudadanos, como sucedió, por ejemplo, en la Segunda Guerra Mundial.

Recuérdese que en aquel conflicto gobernaba la voluntad del pueblo, reflejada en los actos emitidos desde la rama legislativa del poder público. En esta época, se forjó una ciudadanía intolerante, formalmente moralista y sumamente sensible (Bachof, 1985: 46), tal como está sucediendo con las repercusiones de la cultura de la cancelación, que serán insostenibles para sociedades que encuentran en el derecho a la dignidad humana el más importante límite al ejercicio de la potestad punitiva en el seno del moderno Estado social y democrático de derecho (Velásquez, 2017: 42).

Adicional a las reflexiones anteriores, con la cultura de la cancelación el castigo,

43. Barba, «Cultura...». 
en su expresión más amplia, desconoce el principio de dignidad humana, ya que si bien desde Beccaria (1993) la pena tiene que tener un fin preventivo, y en efecto, si se cancela a alguien, este no tendrá forma de volver a cometer la conducta censurada, no se le da al reprochado la opción de dirigir sus acciones de acuerdo a lo que le dicte su conciencia, de manera que pueda aprender de sus errores y evitar caer en la reincidencia.

En este orden de ideas, cuando el sujeto es cancelado, se le cercena la posibilidad de reinsertarse en la sociedad, ya que se le excluye, quedando desprovisto de mostrarse como alguien capaz de aprender de sus errores. En estos escenarios termina considerándose tan despreciable el acto cometido, que el cancelado resulta privado de perdón o rectificación. En otras palabras, pasa a ser censurado no el acto, sino la persona, y esta es una de las grandes consecuencias negativas de la cultura de la cancelación, pues termina estigmatizando al individuo, lo que, para los principios del derecho penal, es como si creara un nuevo estatus que excede el labeling approach, pues ahora no solo es desaprobado socialmente quien comete un delito, sino también quien es cancelado.

Por último, pero no menos importante, la cultura de la cancelación también puede llegar a constituirse en un atentado al numeral tercero del artículo 5 de la Convención Americana sobre Derechos Humanos, que establece que la pena no puede trascender del delincuente, pues las personas que cancelan al señalado también terminan desconociendo las obras o aportes que dicho sujeto ha aportado a la sociedad. Como pasó con la escritora Margaret Atwood o al difunto Rey del Pop, Michael Jackson, que tras el estreno del documental Leaving Neverland, en el que se lo acusa de ser un abusador sexual de menores, sus canciones fueron vetadas de diferentes estaciones de radio, ${ }^{44}$ toda vez que se cree que el reproducir la obra del cantante estadounidense se está justificando los actos criminales por los que fue señalado.

\section{Conclusiones}

La cultura de la cancelación, como movimiento social que se desarrolla en las redes sociales de internet, se ha convertido en un medio no institucionalizado a través del cual personas reprenden comportamientos que se consideran moralmente incorrectos a la luz de los estándares de la comunidad, pero que según la ley no constituyen delitos y, por tanto, no son condenables por el derecho penal.

Este movimiento, que nació hace pocos años, a pesar de traer ventajas como crear estándares aceptables de comportamientos y visualizar minorías, como ya se observó, afecta a las personas que son canceladas en un nivel igual o superior al

44. Grant Tucker, «Michael Jackson songs dropped from Radio 2», The Times, 3 de marzo de 2019, disponible en https://bit.ly/3JhgeTk. 
empleado por parte de los órganos jurisdiccionales. Por ejemplo, la persona cancelada muchas veces no logra ser escuchada o, a pesar de ser declarada inocente o ser judicializada por la ley, sigue siendo rechazada y desvinculada de su círculo laboral, político y social.

Por otro lado, desde el punto de vista del derecho penal, se han creado unos principios rectores que propenden mantener el orden en el complejo sistema social; es por esta razón que existen límites al reproche que se le hace a que es judicializado por presuntamente cometer un delito, por medio de derechos como la presunción de inocencia, el debido proceso y la proporcionalidad entre la pena y el daño ocasionado, entre otros.

En el caso de la cultura de la cancelación, estos límites - que han sido una construcción jurídica de años- no se respetan, pues, al tachar y viralizar en redes sociales el «error» de un famoso o persona del común, se termina desprotegiendo de manera injustificada sus prerrogativas y se otorga a los usuarios de las redes el poder de juzgar y condenar, cuando este le pertenece única y exclusivamente al derecho penal y sus autoridades.

En este orden de ideas, y según lo desarrollado a lo largo de este artículo, se puede concluir, primero, que - tal y como están las cosas - la cultura de la cancelación es un movimiento que va a seguir tomando relevancia y, en esa misma medida, seguirá afectando de manera desmesurada a aquellas personas que según las redes sociales merezcan ser canceladas. Por tanto, debe pensarse en formas para limitar los daños que se le ocasionan al cancelado, aunque aún no es claro cómo, pues este movimiento no es una forma institucionalizada de regulación social y el internet es un medio libre, cuyo control es extremadamente difícil.

Teniendo en cuenta lo anterior, en segunda medida se concluye que, dado que la cultura de la cancelación es un fenómeno social nuevo que necesita estudiarse y entenderse más, la mejor manera de contrarrestar sus consecuencias nocivas es a partir de la educación y la conciencia que tomen los usuarios de redes sociales sobre el principio de proporcionalidad entre la ofensa y el castigo social que se le da al cancelado pues a través de la sistematización de delimitación de los casos se observa cómo, entre más grave es considerado el hecho reprochable por los usuarios de las redes sociales, mayor es la falta de proporcionalidad de la reacción.

En este mismo sentido, como usuarios de redes sociales, las personas también necesitan reflexionar sobre lo que publican, su comportamiento en comunidad y el uso que se le da a la información, pues no puede perderse de vista que el nacimiento de la cultura de la cancelación se debe a la gran cantidad de conductas - que van desde chistes malintencionados y videos violentos- que vulneran sensibilidades y que se busca sean reprobados para que no se repitan.

Lo anterior también permite concluir que, si bien es cierto que hay poca credibilidad ante los sistemas de justicia, esto no quiere decir que la sociedad se encuentra en 
la potestad para condenar conductas que a la luz de la ley no son consideradas delito, ya que no transgreden bienes jurídicos protegidos. De esta forma, parte de los límites de este movimiento están en el respeto a los sistemas judiciales y a las razones que estas han instituido para determinar qué es o no un delito.

Por último, dado que este movimiento es relativamente nuevo y aún sigue desarrollándose, es necesario explorarlo más a fondo desde otras disciplinas para poder identificar de qué forma puede regularse sin que se vulneren los derechos de los que han cometido la conducta reprochable socialmente, pero que tampoco se coarte la libertad de expresión.

\section{Referencias}

Aggarwal, Rachi y Adam M. Brenner (2020). «\#MeToo: The role and power of bystanders (aka us)». Academic Psychiatry, 44: 5-10. DOI: 10.1007/s40596-019-01173-0. Agudelo, Nodier (1987). Crítica y control del poder punitivo del Estado. Bogotá: Temis.

Anderson-Lopez, Jonina, R. J. Lambert y Allison Budaj (2021). «Tug of war: Social media, cancel culture, and diversity for girls and the 100». KOME, 9 (1): 64-84. DOI: 10.17646/KOME.75672.59.

Aguirre, Julio (2011). Introducción al análisis de redes sociales. Documentos de Trabajo, 82, Centro Interdisciplinario para el Estudio de Políticas Públicas, Buenos Aires.

BACHOF, Otto (1985). Jueces y constitución. Madrid: Civitas.

Baratta, Alessandro (2004). Criminología crítica y crítica del derecho penal. Trad. de Álvaro Búnster. Buenos Aires: Siglo XXI.

Beccaria, Cesare (1993). Tratado de los delitos y de las penas. Trad. por Guillermo Cabanellas. Buenos Aires: Heliastra.

BERNAL, Carlos (2014). El principio de proporcionalidad y los derechos fundamentales. Bogotá: Universidad Externado de Colombia.

Bustos, Juan (1999). «Principios garantistas del derecho penal y del proceso penal». Nuevo Foro Penal, 12 (60): 105-113. Disponible en https://bit.ly/3evzWJL.

Carbonell, Miguel (2016). La vida en línea: El impacto de las redes sociales en todo lo que hacemos. Madrid: Tirant lo Blanch.

Cornejo, Marqueza y María Lourdes Tapia (2011). «Redes sociales y relaciones interpersonales en internet». Fundamentos en Humanidades, 12 (24): 219-229. Disponible en https://bit.ly/3z4VaYs.Duque, Richard B., Robert Rivera y E. J. LeBlan (2021). "The active shooter paradox: Why the rise of cancel culture, "Me Too", Antifa and Black Lives Matter... matters». Aggression and Violent Behavior, 60: 1-16. DOI: 10.1016/j.avb.2020.101544. 
HütT, Harold (2012). «Las redes sociales: Una nueva herramienta de difusión». Reflexiones, 91 (2): 121-128. Disponible en https://bit.ly/3z8So4n.

Leyva, Manuel y Larisbel Lugo (2015). «La influencia de Beccaria en el derecho penal modern». Derecho Penal y Criminología, 36 (101): 133-151. DOI: 10.18601/01210483. v36n101.05.

Mir Puig, Santiago (2011). Bases constitucionales del derecho penal. Madrid: Iustel.

Montesquieu (1906). El espíritu de las leyes. Tomo 1. Madrid: Librería General de Victoriano Suarez.

Norris, Pipa (2021). «Cancel culture: Myth or reality?». Political Studies, 1: 1-30. DOI: $10.1177 \% 2$ Foo 323217211037023 .

Ros, Hailey (2020). «With(stan)ding cancel culture: Stan Twitter and reactionary fandoms». Tesis de grado, Muhlenberg College Media \& Communication. Disponible en https://bit.ly/3sMOtsT.

Ros-Martín, Marcos (2009). «Evolución de los servicios de redes sociales en internet». El Profesional de la Información, 18 (5): 552-557. DOI: 10.3145/epi.2009.sep.10.

Roxin, Claus (2007). «¿Es la protección de bienes jurídicos una finalidad del derecho penal?». En Roland Hefendehl, Andrew von Hirsch, Rafael Alcácer Guirao, María Martín Lorenzo e Iñigo Ortiz de Urbina Gimeno (editores), La teoría del bien jurídico (pp. 433-448). Madrid: Marcial Pons.

SAINT-Louis, Hervé (2021). «Understanding cancel culture: Normative and unequal sanctioning». First Monday, 26 (7). DOI: 10.5210/fm.v26i7.10891.

SotomaYor, Juan y Fernando Tamayo (2017). «Dignidad humana y derecho penal: Una difícil convergencia. Aproximación al contenido constitucional de la norma rectora del artículo 1 del Código Penal colombiano». Revista de Derecho de la División de Ciencias Jurídicas de la Universidad del Norte, 48: 21-53. Disponible en https://bit.ly/3Z27KYw.

Teixeira Da Silva, Jaime (2021). «How to shape academic freedom in the digital age? Are the retractions of opinionated papers a prelude to "cancel culture" in academia?». Current Research in Behavioral Sciences, 2: 1-6. DOI: 10.1016/j. crbeha.2021.100035.

VAN DijCK, José (2019). La cultura de la conectividad: Una historia crítica de las redes sociales. Trad. de Hugo Salas. Buenos Aires: Siglo XXI.

Velásquez, Fernando (2017). Fundamentos de derecho penal parte general. 1. ${ }^{\mathrm{a}}$ ed. Bogotá: Ediciones Jurídicas Andrés Morales.

Zaffaroni, Eugenio Raúl (1998). Tratado de derecho penal parte general. Buenos Aires: Ediar.

-. (2007). Manual de derecho penal parte general. 2. ${ }^{\mathrm{a}}$ ed. Buenos Aires: Ediar. 


\section{Sobre los autores}

Karen Isabel Cabrera Peña es abogada de la Universidad del Norte. Doctora en Derecho de la Universidad del Rosario. Profesora asistente del Programa de Derecho de la Universidad del Norte. Su correo electrónico es cabrerak@uninorte.edu.co. (DD https://orcid.org/oooo-0003-1285-5500.

Carlos Alberto Jiménez Cabarcas es abogado. Especialista en derecho penal y Magíster en Derecho con énfasis en Ciencias Penales y Criminológicas. Profesor de la Universidad Libre Seccional Barranquilla. Su correo electrónico es carlosa.jimenezc@unilibre.edu.co. (D) https://orcid.org/oooo-0002-7301-4265. 


\title{
REVISTA CHILENA DE DERECHO Y TECNOLOGÍA
}

La Revista Chilena de Derecho y Tecnología es una publicación académica semestral del Centro de Estudios en Derecho Informático de la Facultad de Derecho de la Universidad de Chile, que tiene por objeto difundir en la comunidad jurídica los elementos necesarios para analizar y comprender los alcances y efectos que el desarrollo tecnológico y cultural han producido en la sociedad, especialmente su impacto en la ciencia jurídica.

\author{
EDITOR GENERAL \\ Daniel Álvarez Valenzuela \\ (dalvarez@derecho.uchile.cl) \\ SITIO WEB \\ rchdt.uchile.cl \\ CORREO ELECTRÓNICO \\ rchdt@derecho.uchile.cl \\ LICENCIA DE ESTE ARTÍ́CULO \\ Creative Commons Atribución Compartir Igual 4.o Internacional
}

\begin{abstract}
s
La edición de textos, el diseño editorial

y la conversión a formatos electrónicos de este artículo

estuvieron a cargo de Tipográfica

(www.tipografica.io).
\end{abstract}

